\title{
OURICURI
}

\section{ECO-EPIDEMIOLOGIA DE ACIDENTES CAUSADOS POR LEPIDÓPTEROS EM HUMANOS NO ESTADO DA BAHIA}

\author{
Isabela Franca SOUSA ${ }^{1}$; Artur Gomes Dias LIMA² \\ ${ }^{1}$ Biomédica - Escola Baiana de Medicina e Saúde Pública, Salvador-BA. E-mail: \\ chordata.brasilis@gmail.com; \\ 2Professor da Universidade do Estado da Bahia - UNEB, no Departamento Ciências da Vida - DCV Campus \\ I e da Escola Baiana de Medicina e Saúde Pública, Salvador-BA. E-mail: agdlima@uneb.br \\ http://doi.org/10.29327/ouricuri.v8.i1.a4
}

\begin{abstract}
Resumo: Acidentes com lepidópteros peçonhentos sempre foram um potencial risco para habitantes de regiões rurais e estes vêm se tornando uma realidade para cidades, devido ao aumento de sua população em decorrência às mudanças em seu habitat natural. Considerando os agravos sintomáticos relacionados a certas espécies, onde complicações ocasionalmente podem evoluir ao óbito, este artigo tem como objetivo traçar um perfil epidemiológico no estado da Bahia, a fim de descrever as principais espécies de sua região e suas respectivas lesões pelo contato. Nele foram identificadas 703 notificações, correspondendo a 42,2\% dos municípios baianos, que demonstram maiores ocorrências em homens, principalmente durante a faixa etária laboral. Foi possível averiguar neste trabalho as tendências sazonais para os acidentes e, a partir da análise desses dados obtidos, e o levantamento de hipóteses para as condições onde os mesmos ocorrem, espera-se assim contribuir para a discussão do assunto que, em geral, é negligenciado e subnotificado.
\end{abstract}

Palavras-chaves: Lepidopterismo; Erucismo; Lepidoptera.

\section{Eco-epidemiology of accidents by lepidopterans in humans from Bahia state.}

\begin{abstract}
Accidents with venomous Lepidoptera have always been a potential risk for residents in rural areas and it's also becoming common reality for cities as well, due to population increase in consequence of changes in their natural habitat. As a result of the symptomatic aggravations led by certain species, in which complications occasionally might lead to death, this article aims to outline an epidemiological profile from Bahia's state, so to describe the state's main species and their respective injuries prior to contact. In this work 703 notifications of were identified, corresponding to a total of $42,2 \%$ of Bahia municipalities, displaying greater occurrences among males, especially during working age range. It was possible to infer the seasonal tendencies for these accidents and, from this analysis as well as raising hypothetical questions for the occurring conditions, it's expected to contribute for a discussion on a subject matter that is generally neglected and underreported.
\end{abstract}

Key words: Lepidopterism; Erucism; Lepidoptera.

\section{INTRODUÇÃO}

A ordem Lepidoptera é segunda maior ordem de insetos no Brasil (RAFAEL, 2012) e é constituída de insetos cuja forma adulta exibe asas escamosas, como seu próprio nome sugere, e corpo vermiforme na fase larval. Um estudo no Departamento de Entomologia, em 1976, sobre a evolução de lepidópteros descreveu, através de uma análise de raros fósseis, que uma ordem de lepidópteros coevoluiu em um relacionamento simbiótico com os primeiros vegetais produtores de

Revista Ouricuri, Juazeiro, Bahia, v.8, n.1. p.037-047.jan./jun., 2018. http://www.revistas.uneb.br/index.php/ouricuri | ISSN 2317-0131 
flores e frutos (angiospermas) durante o início do período Cretáceo (SHIELDS, 1976). Estima-se que essa ordem de lepidópteros, similares a mariposas, já existiam há 140 milhões de anos, enquanto as borboletas surgiram mais recentemente, há 40 milhões (MORAES, 2009).

As diferenças anatômicas entre borboletas e mariposas vão muito além dos seus hábitos diurnos ou noturnos, e vão desde o posicionamento de suas asas enquanto em repouso, o formato e complexidade estrutural de suas antenas, do desenvolvimento de suas patas traseiras até o modo com que realizam sua metamorfose, onde pode haver formação de crisálidas ou com desenvolvimento de casulos, salvo suas respectivas exceções (SOUSA, 2015). Apesar de possuírem famílias classificadas como peçonhentas, os insetos da ordem Lepidoptera possuem importância e impacto nos aspectos ecológico, econômico e médico.

Ecologicamente, possuem sua devida relevância durante sua fase adulta, já que ao se alimentarem do néctar de flores acabam por carregar seu pólen, atuando assim como importantes polinizadoras (SOUSA, 2015). Servem também como fonte de alimento para uma cadeia gigantesca de animais, como insetos maiores, aracnídeos, anfíbios, entre outros, tanto em sua forma larval quanto adulta. Para os humanos, borboletas e mariposas possuem uma influência econômica positiva, quando são utilizados para produção de materiais sofisticados como a seda, e negativa, quando os mesmos destroem plantações enquanto se alimentam na sua forma larval (MORAES, 2009; SOUSA, 2015).

Existem características que ambas mariposas e borboletas desenvolveram devido à necessidade em comum de se defenderem contra potenciais predadores, surgindo assim exemplares capazes de produzir suas próprias toxinas, como mecanismos de defesa biológicos, afim de desestimular a sua caça no seu estágio mais vulnerável. A maioria das espécies não são prejudiciais à saúde de seres humanos, enquanto as famílias de lepidópteros como Megalopygidae, Saturniidae, Arctiidae, e Limacodidae, caracterizadas de maior importância médica no Brasil, possuem o potencial de causar lesões graves e algumas vezes irreversíveis (CARDOSO, 2005; MORAES, 2009).

Os primeiros registros de ocorrências de acidentes com lagartas de lepidópteros no Brasil foram descritos em 1912 por Zoroastro Alvarenga (GARCIA e DANNI-OLIVEIRA, 2007). No entanto, de acordo com as cartas de José de Anchieta para Portugal, era de conhecimento dos índios a reação inflamatória causada pelas cerdas urticantes das lagartas, que as friccionavam contra seus órgãos sexuais para causar edema e facilitar a relação sexual, deixando-os com lesões muitas vezes extensas e graves (CARDOSO, 2005; MORAES, 2009).

Os tipos de acidentes relacionados à forma larval desses insetos peçonhentos são denominados como erucismo, e quando ocorrem com os adultos são denominados lepidopterismo (CARDOSO, 2005; MORAES, 2009). Esses incluem casos clínicos característicos de dermatite urticante, provocados pelo contato com espículas na forma larval de diversos gêneros de lepidópteros, assim como pelo contato com as cerdas de mariposas fêmeas do gênero Hylesia sp.

Revista Ouricuri, Juazeiro, Bahia, v.8, n.1. p.037-047.jan./jun., 2018. 
(em sua forma adulta); periartrite falangeana, provocada pelo contato com as cerdas de larvas do gênero Premolis sp. e finalmente a síndrome hemorrágica, talvez a situação mais grave desses acidentes, caracterizada pelo contato com a forma larval de lepidópteros do gênero Lonomia sp. (MINISTÉRIO DA SAÚDE, 2001).

Casos de lepidopterismo no Brasil tem como responsáveis as fêmeas do gênero Hylesia sp., enquanto em sua forma adulta e alada, mantém em seu abdômen cerdas urticantes (MINISTÉRIO DA SAÚDE, 2001; CARDOSO, 2005), que se soltam ao bater de suas asas ou quando se chocam contra estruturas à procura da luz. Essas, quando liberadas, formam uma "nuvem" de partículas flutuantes e as mesmas podem se fixar em tecidos podendo acometer os indivíduos mais desavisados (MOREIRA, 2007). Esses tornam-se particularmente mais frequentes durante os meses mais quentes e chuvosos, sendo evidenciados surtos epidêmicos nessas épocas do ano em áreas rurais ou próximas. Apesar de existirem controvérsias quanto ao mecanismo de ação da toxina existente ou não nas cerdas do inseto, é possível observar a dermatite caracterizada numa típica lesão pápulo-pruginosa (CARDOSO, 2005; MOREIRA, 2007) com a participação da histamina na produção da reação inflamatória (DINEHART, 1987).

O erucismo é o acidente que ocorre mais frequentemente e é principalmente causado por três famílias de mariposas: Megalopygidae, Saturnidae e Arctiidae. Nestas, possuem destaque os gêneros Podalia sp. e Megalopyge sp. na família Megalopygidae; Automeris sp., Hylesia sp., Dirphia sp. e Lonomia sp. para Saturnidae (CARDOSO, 2005) e para a família Arctiidae, o único exemplar considerado de importância médica é a Premolis semirufa (MORAES, 2009; VILLAS-BOAS, 2013).

Normalmente são caracterizados apenas por uma dermatite urticante, seguida de edema, eritema, sensação de queimação e prurido local, muito dolorosa para os acometidos, podendo ser acompanhado também por lesões puntiformes no local de contato com as cerdas, evoluindo ou não para a formação de bolhas e necrose local (MINISTÉRIO DA SAÚDE, 2001; CARDOSO e HADDAD JÚNIOR, 2005; HADDAD, 2009).

Existem espécies que, além do quadro de erucismo característico, também levam ao desenvolvimento de complicações mais graves. São espécies como Lonomia achelous e Lonomia obliqua, cujos acidentes resultam em síndromes hemorrágicas devido às toxinas fibrinolíticas contidas em suas espículas (MINISTÉRIO DA SAÚDE, 2001; GARCIA e DANNI-OLIVEIRA, 2007; SILVA, 2007) com complicações desde insuficiência renal aguda até o próprio óbito (WEN, 2009). Outra espécie geradora de mais complicações é Premolis semirufa, causadora da pararamose, uma doença ocupacional incapacitante entre seringueiros, de difícil diagnóstico pela sua cronicidade e suas lesões irreversíveis (DIAS, 1973; COSTA, 2009), levando à perda de mobilidade de articulações que entraram em contato repetitivo com as cerdas da larva (MINISTÉRIO DA SAÚDE, 2001; COSTA, 2009; VILLAS-BOAS, 2013). Devido à envenenamentos relacionados ao contato com lagartas do gênero Lonomia, que por possuir uma alta predominância principalmente nas regiões de centro ao sul do país (GARCIA e DANNI-OLIVEIRA, 2007), um quadro clínico

Revista Ouricuri, Juazeiro, Bahia, v.8, n.1. p.037-047.jan./jun., 2018. 
característico de síndrome hemorrágica e altas tendências de alcançar proporções epidêmicas (CAOVILLA, 2007), os casos de notificação sobre incidentes com lepidópteros passaram a ser mais pesquisados, definindo também certas características para as outras espécies (MORAES, 2009).

Diante do exposto, a fundamentação deste trabalho tem como objetivo elaborar um perfil epidemiológico do estado da Bahia, evidenciando os tipos de incidentes que lepidópteros em estágio larval e adulto podem acarretar, tal como suas respectivas lesões e consequentes patologias. Assim, é importante ressaltar as principais situações onde estes acidentes ocorrem, ao levar em consideração a questão comportamental destes animais e como seres humanos podem entrar em contato com esses em seu dia a dia.

\section{METODOLOGIA}

O presente estudo é ecológico do tipo misto e epidemiológico de série temporal e com avaliação espacial, utilizando a base de dados do SINAN. Foi realizado com base em artigos relacionados a acidentes com lepidópteros, com enfoque em aspectos epidemiológicos, dados descritivos quanto aos tipos de lesões, sobre as regiões no Brasil onde determinadas espécies mais predominam, sua disposição geográfica e temporalidade. Foram utilizados artigos disponíveis no banco de dados SCIELO, teses de mestrado disponíveis online, artigos de revistas online, dados epidemiológicos fornecidos pelo DATASUS, dados demográficos do IBGE, livros acadêmicos e manuais teóricos de instituições como o Instituto Butantan, EMBRAPA e Ministério da Saúde, mas relevantes do ponto de vista do enfoque desta revisão.

Foram utilizadas literaturas diversas, provenientes de artigos científicos à livros acadêmicos com base em informações relevantes sobre o assunto, retratando dados epidemiológicos, variedade de lesões causadas por diferentes espécies, relatos de casos e os principais grupos de risco para estes acidentes.

Não foram incluídos neste trabalho dados aprofundados referentes aos mecanismos de ação específicos de suas respectivas toxinas, dados comparando a efetividade dos demais tratamento para as lesões causadas nos acidentes, anatomia morfológica dos insetos, anatomia de suas cerdas e seu ciclo biológico.

\section{RESULTADOS}

A avaliação das informações obtidas no banco de dados do Sistema de Informação de Agravos de Notificação do Brasil (SINAN) permitiu observar a progressão dos casos registrados de acidentes com lagartas peçonhentas no estado da Bahia. Visando descrever o perfil epidemiológico dos agravos por lepidópteros, foram separadas as notificações por gênero, faixa etária, ano e mês de ocorrência. É válido ressaltar, no entanto, que até então os dados referentes aos anos de 2013, 2014 e 2015 tiveram sua última atualização na data de 02/10/2015 e podem ainda estar sujeitos à revisão. 
Ao observar os dados apresentados na figura 1, é possível perceber que gradualmente ocorreu um aumento no número de ocorrências registradas ao comparar as sequências ao longo dos anos, sendo seu apogeu no ano de 2014. Dos 417 municípios da Bahia, 176 (42,2\%) tiveram pelo menos uma notificação de acidente, totalizando cerca de 703 incidentes registrados em todo o estado.

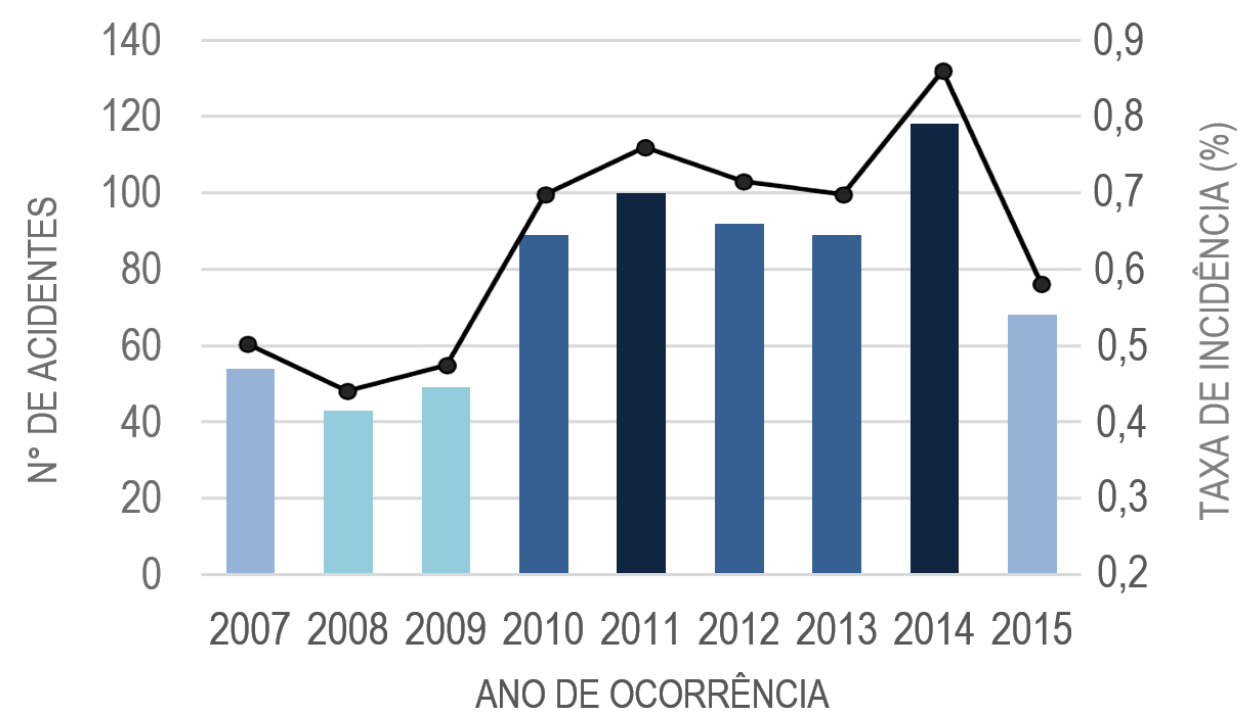

Figura 1. Número de notificações totais e taxa de incidência de acidentes por lepidópteros peçonhentos no estado da Bahia nos anos de 2007 a 2015.

O mapa representando o estado da Bahia (Figura 2) demonstra os principais municípios com maior ocorrência registros de acidentes totais nos anos em questão, incluindo todos os municípios que possuíram, pelo menos, um registro neste intervalo de tempo. Desses, os municípios que notificaram maior quantidade de casos foram Salvador e Santo Estevão, com 132 e 50 casos totais, respectivamente. Ressalta-se também, que foram poucas ocorrências nos municípios da mesorregião do Extremo Oeste Baiano e Vale do São Franciscano, sobre contraste da grande distribuição de casos em comparação a região metropolitana de Salvador ao meio entre mesorregiões de Centro Sul e Centro Norte Baiano. 


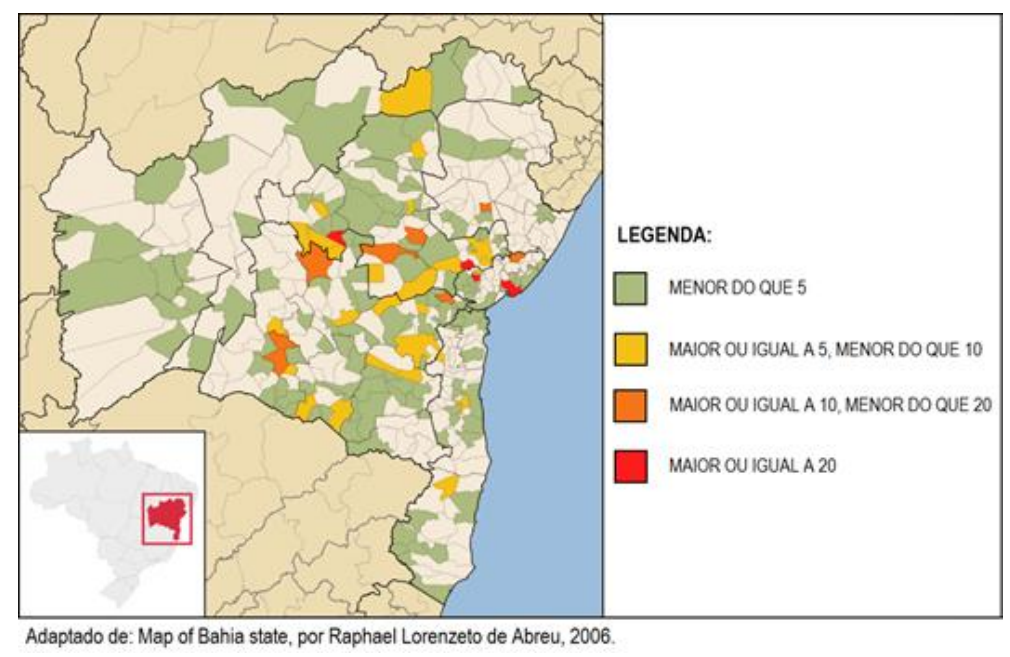

Figura 2. Áreas de ocorrência de acidentes pela quantidade de casos com lepidópteros peçonhentos no estado da Bahia durante o período de 2007 a 2015.

Com relação a gênero, é possível perceber uma ocorrência consideravelmente maior com os homens comparativamente às mulheres (Figura 3). O maior contraste entre esses casos se encontra no ano de 2015, sendo duas vezes superior aos acidentes com mulheres. Em geral, a relação destes é equivalente à $46 \%$ para acidentes com o sexo feminino e $54 \%$ para o sexo masculino. Analisando as ocorrências por faixa etária é possível constatar que as faixas de idade de 20 a 39 e 40 a 59 anos são as mais acometidas entre todos os outros grupos (Figura 4). Seguido destes, o maior número de notificações foi registrado entre as idades de 1 a 14 anos, apesar de aparecerem em uma menor proporção. Por fim, ao observar os dados adquiridos por mês de ocorrência (Figura 5), é possível conferir um notável aumento de acidentes iniciando no mês de abril e atingindo seu ápice em maio, e como contraste os meses de menor ocorrência são justamente os últimos meses do ano, outubro, novembro e dezembro.

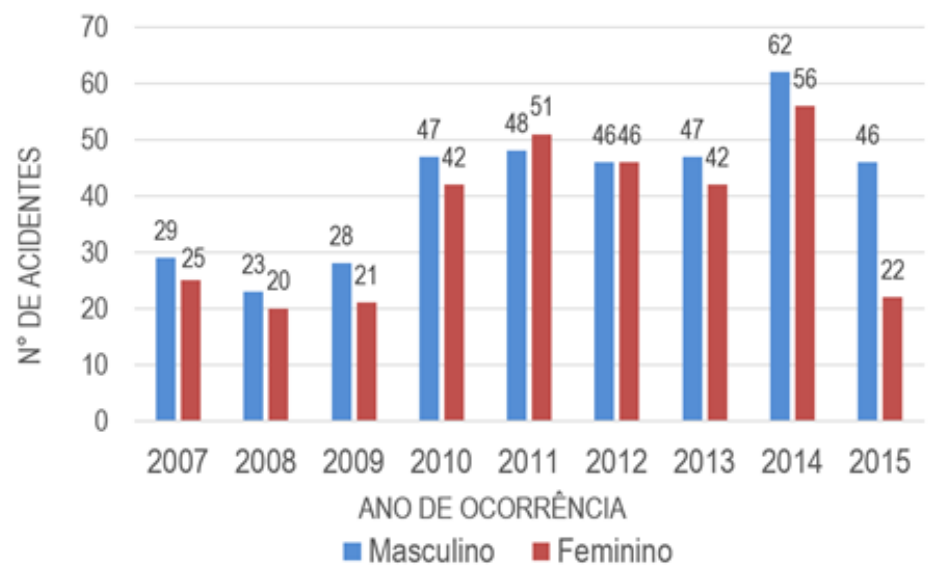

Figura 3. Notificações totais de acidentes por gênero nos anos de 2007 a 2015 de acidentes por lepidópteros peçonhentos no estado da Bahia. 


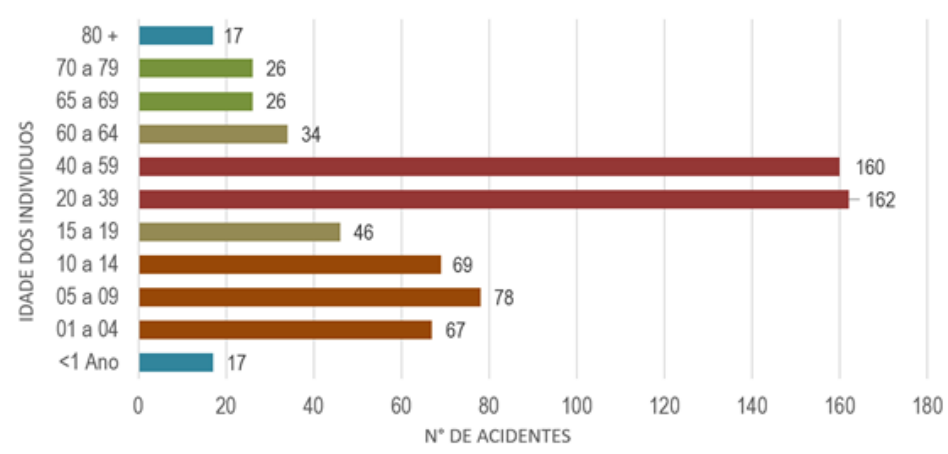

Figura 4. Relação de ocorrências totais por faixa etária nos anos de 2007 a 2015 de acidentes por lepidópteros peçonhentos no estado da Bahia.

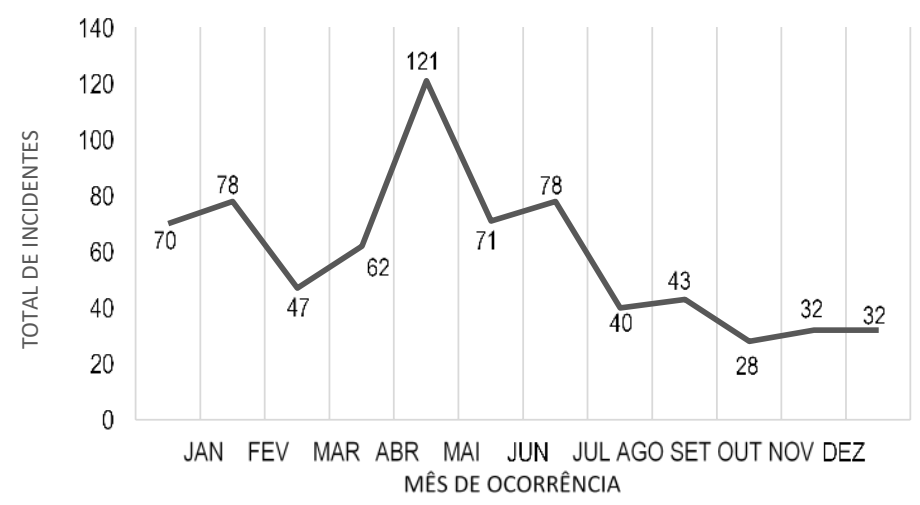

Figura 5. Notificações totais de acidentes por lepidópteros peçonhentos no estado da Bahia por mês de ocorrência nos anos de 2007 a 2015.

\section{DISCUSSÃO}

Seres humanos já possuíam um histórico de contato com estes insetos muito anterior à documentação dos mesmos. Dessa forma, a própria origem de tratamentos para a intoxicação torna-se controversa ou discutível, considerando o quanto as noções empíricas passadas por gerações, ou seja, a cultura popular, ainda influenciam fortemente a terapêutica destes acidentes, o que dificulta a investigação científica dos mesmos (CAOVILLA, 2007; VILLAS-BOAS, 2013).

É provável que o aumento no número de acidentes com estes insetos seja proporcional às alterações ecológicas, como o desmatamento de regiões arbóreas nativas (CARDOSO e HADDAD, 2005; ESPINDULA, 2009; WEN, 2009;), com redução de predadores naturais para seu controle populacional (WEN, 2009). As lagartas, em geral, provocam surtos sazonais em meses de características mais quentes e chuvosos (CARDOSO e HADDAD, 2005). No atual trabalho, o mês de maio mostrou-se o mais incidente e, através de uma análise de dados climatográficos, é possível inferir que os acidentes aumentam na estação de outono (CPTEC/INEP). Em outras fontes, analisando principalmente os casos com o gênero Lonomia nas regiões Sul e Sudeste, ocorrem nos meses de fevereiro e março (GARCIA e DANNI-OLIVEIRA, 2007) como meses de aumento de casos, enquanto outras, os meses de verão, a partir de novembro (WEN, 2009). Sua sazonalidade no estado da Bahia, diante dos dados obtidos neste trabalho, pôde ser relacionada ao término do

Revista Ouricuri, Juazeiro, Bahia, v.8, n.1. p.037-047.jan./jun., 2018. 
ciclo de chuvas do outono. Diante disto, vale considerar a possibilidade deste período coincidir com a fase larval final dos insetos, necessitando, no entanto, de aprofundamento em estudos relacionados à biologia destes insetos.

Para os grupos de risco, é possível inferir que os trabalhadores de áreas mais arborizadas ou rurais são os principais acometidos, já que a maioria destes acidentes reside em locais próximos ao habitat desses insetos (GARCIA e DANNI-OLIVEIRA, 2007). Esta é a principal sugestão de ocorrência deste estudo, o qual aponta que são muito mais prováveis de serem relacionados aos acidentes ocupacionais, pelas idades mais acometidas estarem relacionadas com a faixa etária laboral que, em média, está situada entre os 20 a 59 anos. As crianças, de faixa etária por volta de 01 aos 14 anos, também podem ser consideradas um grupo de risco, já que por sua curiosidade e descuido podem vir a entrar em contato com espécies de cores mais vibrantes e aparências mais chamativas.

É possível perceber que, fora as espécies de interesse médico, a maioria desses acidentes não exercem risco imediato além do desconforto das reações inflamatórias e lesões cutâneas iniciais, possuindo um eventual regresso de sintomas num período de 24 à 48 h (HADDAD, 2009), onde é possível inferir que acometidos por estes acidentes tendem a procurar atendimento médico ao se mostrarem mais graves. Essas condições dificultam a pesquisa e o mapeamento epidemiológico das diferentes espécies que mais resultam em acidentes. Com intuito de discussão, pode-se citar como exemplo a letalidade do veneno da $L$. achelous e $L$. obliqua que, devido a complicações associadas às hemorragias maciças, vêm sido associadas com eventuais óbitos (WEN, 2009). Um grande avanço ocorreu quando, assim como em acidentes ofídicos, surgiu a possibilidade de desenvolver um soro hiperimune específico para neutralizar efetivamente seu veneno (CAOVILLA, 2007), evitando assim maiores complicações e diminuindo a probabilidade do desenvolvimento de suas complicações hemorrágicas, tornando a ocorrência de óbitos relacionada sistematicamente com o atraso ou falha no diagnóstico do indivíduo acometido (WEN, 2009).

Existem, no entanto, documentações sobre agravos sintomáticos associadas à outras espécies que não são tão estudadas quanto esta. Vão desde o contato com as cerdas de mariposas do gênero Hylesia, que ocasionalmente podem acarretar irite e ceratite (HADDAD, 2009), até espécies não tão comentadas na literatura como Dirphia sp., um saturnídeo anatomicamente similar à Lonomia sp. cuja toxina, ainda que pouco estudada, pode apresentar quadros sintomatológicos de dermatites à danos renal e hepático (MARQUES, 2009).

Através de estudos pela literatura disponível, as possíveis espécies que podem causar acidentes em indivíduos no estado da Bahia são as Lonomia obliqua, Periga insidiosa (MORAES, 2009), Dirphia avia, Dirphia moderata (MARQUES, 2009) e Hylesia sp. (MOREIRA, 2007). No entanto, a possibilidade da existência de exemplares da espécie Premolis semirufa ainda não pode ser descartada, considerando que diversos municípios no baixo Sul da Bahia desenvolvem extensivas atividades de produção agrícola com seringueiras (MARQUES, 2000), cujas folhas são

Revista Ouricuri, Juazeiro, Bahia, v.8, n.1. p.037-047.jan./jun., 2018. 
o principal atrativo por ser o alimento desse inseto (VILLAS-BOAS, 2013).

Acidentes por animais peçonhentos em geral não são prioridade em programas de saúde pública, sendo, portanto, um entre muitos outros problemas de saúde negligenciados em todo o planeta (MESCHIAL, 2013), o que compromete a execução de medidas preventivas conforme a necessidade ou gravidade das lesões. A negligência profissional ou o desconhecimento da população acaba gerando subnotificações, torna-se um problema considerando as complicações que estes acidentes podem causar.

A ausência de classificação de espécies no banco de dados SINAN é um fator que dificulta a criação de um panorama epidemiológico específico e preciso, impedindo o planejamento de medidas profiláticas, tal como melhor apresentar o problema para o público geral.

A análise e descrição efetiva dos sintomas, bem como o reconhecimento da espécie é essencial para obter um bom diagnóstico e acompanhamento efetivo diante das diferentes necessidades que cada acometimento provoca, incluindo desde o tratamento dos sintomas iniciais a quaisquer possíveis complicações que eventualmente possam ocorrer.

Diante do exposto, é importante para a população que, mesmo que em um nível básico, tenha conhecimento dos riscos de acidentes por lepidópteros e sua eventual gravidade. Devem ser implantadas medidas preventivas individuais e coletivas, para se evitar acidentes.

O poder público deve estar atento ao fato que este aumento de acidentes registrados ao passar dos anos, vem expondo a população. Fatores como as estações do ano, clima, urbanização, desmatamento, paisagismo e crescimento populacional, que podem estar influenciando no ciclo de vida do inseto e, possivelmente, aumentando o número de acidentes.

\section{REFERÊNCIAS}

BRASIL. Ministério da Saúde. Departamento de Informática do Sistema Único de Saúde (DATASUS). Bahia. Disponível em: www2.datasus.gov.br/DATASUS/index.php. Acesso em 05 maio 2016.

BRASIL. Ministério da saúde. Manual de diagnóstico e tratamento de acidentes por animais peçonhentos. 2ª edição. Brasília: Fundação Nacional de Saúde, 2001.

BRASIL. Ministério do Planejamento, Orçamento e Gestão. Instituto Brasileiro de Geografia e Estatística (IBGE). Bahia. Disponível em: http://cidades.ibge.gov. Acesso em: 05 maio 2017.

CAOVILLA, J. J.; GUARDAO, E. J. B. Avaliação da eficácia do soro antilonômico na reversão da síndrome hemorrágica causada por contato com lagartas da Lonomia obliqua (Lepidoptera, Saturniidae). Universidade de Passo Fundo, Universidade Federal do Rio Grande do Sul, 2007.

CARDOSO, A. E.; HADDAD JÚNIOR, V. Acidentes por lepidópteros (larvas e adultos de mariposas): estudo dos aspectos epidemiológicos, clínicos e terapêuticos. Anais Brassileiros de Dermatologia, 571-578, 2005.

COSTA, R. M. P. In: CARDOSO J. L. C.; FRANÇA, F. O. S.; WEN, F. H.; MÁlAQUE, C. M. S.; HADDAD JÚNIOR, V. Animais peçonhentos no Brasil: Biologia, clínica e terapêutica dos acidentes. 2ª edição, Sarvier, 2009. p. 249- 252. 
CPTEC/INPE. Estações do ano. Ministério da Ciência e Tecnologia.1995 - 2017. Disponível em: www.clima1.cptec.inpe.br/ estacoes/. Acesso em: 15 maio 2017.

DIAS, L. B.; AZEVEDO, M. C. Pararama, doença causada por larvas de lepidóptero: Aspectos experimentais. Instituto Evandro Chagas, Fundação Instituto Oswaldo Cruz, Belém, Pará. Boletin de la oficina sanitária pan-americana, Vol VII, n³. Publicado em setembro, 1973.

DINEHART, S. M.; JORIZZO, J. L.; SOTER, N. A.; NOPPAKUN, N.; VOSS, W. R.; HOKANSON, J. A.; SMITH, E. B. Evidence for Histamine in Urticating Hairs of Hylesia Moths. The Journal of Investigative Dermatology, 88(6), 691-693, 1987.

ESPINDULA, A. P.; FERRAZ, M. L. F.; FERREIRA, A. A.; FALEIROS, A. C. G.; OLIVEIRA, F. A.; TEIXEIRA, V. P. A. Acidente humano por Lepidópteros. Revista de Patologia Tropical, 38, 2009.

GARCIA, C. M.; DANNI-OLIVEIRA, I. M. Ocorrência de acidentes provocados por Lonomia obliqua Walker, no estado do Paraná, no período de 1989 a 2001. Revista da Sociedade Brasileira de Medicina Tropical, 40(2), 242-246, 2007.

HADDAD, V. J. R.; CARDOSO, J. L. C. Erucismo e Lepidopterismo. In: CARDOSO J. L. C.; FRANÇA, F. O. S.; WEN, F. H.; MÁLAQUE, C. M. S.; HADDAD JÚNIOR, V. Animais peçonhentos no Brasil: Biologia, clínica e terapêutica dos acidentes. $2^{2}$ edição, Sarvier, 2009. p. 236-239.

MARQUES, O. M. CARVALHO, A. J. A.; SANTANA, M. J. S.; GIL-SANTANA, H. R. Registro de Dirphia avia (stoll) e Dirphia moderata Bouvier (Lepidoptera: Saturniidae) no estado da Bahia, Brasil. Magistra, 21, 135-138, 2009.

MARQUES, J. R. Seringueira. Disponível em: www.ceplac.gov.br/ radar/seringueira.htm. Acesso em: 18 maio 2017.

MESCHIAL, W. C.; MARTINS, B. F.; REIS, L. M.; BALLANI, T. S. L.; BARBOZA, C. L.; OLIVEIRA, M. L. F. Internações hospitalares de vítimas de acidentes por animais peçonhentos. Revista da Rede de Enfermagem do Nordeste, 14(2), 311-9, 2013.

MORAES, R. H. P. Lepidópteros de importância médica. In: CARDOSO J. L. C.; FRANÇA, F. O. S.; WEN, F. H.; MÁLAQUE, C. M. S.; HADDAD JÚNIOR, V. Animais peçonhentos no Brasil: Biologia, clínica e terapêutica dos acidentes. $2^{\underline{a}}$ edição, Sarvier, 2009. p. 227-251.

MOREIRA, S. C.; LIMA, J. C.; SILVA, L.; HADDAD JUNIOR, V. Descrição de um surto de lepidopterismo (dermatite associada ao contato com mariposas) entre marinheiros, ocorrido em Salvador, Estado da Bahia. Revista da Sociedade Brasileira de Medicina Tropical, 40(5), 591-593, 2007.

RAFAEL, J. A.; MELO, G. A. R.; CARVALHO, C. J. B.; CASARI, S. A.; CONSTANTINO, R. Insetos do Brasil: Diversidade e Taxonomia. Ribeirão Preto: Holos, 795 p, 2012.

SHIELDS, O. Fossil butterflies and the evolution of lepidoptera. Journal of Research on the Lepidoptera, Department of Entomology, California, 1976.

SILVA, K. R. L. M. Envenenamento pela taturana Lonomia obliqua: estudo das propriedades hemorrágica e inflamatória do veneno em modelos animais. Porto Alegre. Universidade Federal do Rio Grande do Sul, 2007.

SOUSA, E. S. Borboletas e Mariposas. Agência de Informação Embrapa. Disponível em: www.agencia.cnptia. embrapa.br/Agencia16/AG01/arvore/A G01_81_911200585235.html. Acesso em: 15 maio 2017.

VILLAS-BOAS, I. M.; ANDRADE, R. M. G.; BAPTISTÃO, C. C. S.; SANT'ANNA, O. A.; TAMBOURGI, D. V. Characterization of Phenotypes of Immune Cells and Ctytokines Associated

Revista Ouricuri, Juazeiro, Bahia, v.8, n.1. p.037-047.jan./jun., 2018. 
with Chronic Exposure to Premolis semirufa Caterpillar Bristles Extract. Pararama Toxins Activate a Potent Immune Response. PLoS ONE, 8(9), 1-12, 2013.

VILLAS-BOAS, I. M. S. Caracterização biológica e imunoquímica da peçonha da lagarta de Premolis semirufa, agente etiológico da pararamose, doença ocupacional dos seringueiros da Amazônia. Universidade de São Paulo, São Paulo, 2013.

WEN, F. H.; DUARTE, A. C. Acidentes por Lonomia. In: CARDOSO, J. L. C.; SIQUEIRA FRANÇA, F. O.; WEN, F. H.; MALÁQUE, C. M. S.; HADDAD JR., V. Animais peçonhentos no Brasil: Biologia, clínica e terapêutica dos acidentes. $2^{\underline{a}}$ edição, Sarvier, 2009. p. 240-247. 